Research Article

\title{
Incentive and Coordination in the Two-Sided Market: Evidence from the P2P Lending Market
}

\author{
Yingxiu Zhao $\mathbb{D}$ and Baojuan Shi id \\ North China University of Science and Technology School of Economics, Tangshang 063210, China \\ Correspondence should be addressed to Baojuan Shi; shibaojuan@ncst.edu.cn
}

Received 13 September 2021; Revised 22 October 2021; Accepted 22 October 2021; Published 13 November 2021

Academic Editor: Xiao Li

Copyright (c) 2021 Yingxiu Zhao and Baojuan Shi. This is an open access article distributed under the Creative Commons Attribution License, which permits unrestricted use, distribution, and reproduction in any medium, provided the original work is properly cited.

\begin{abstract}
Two-sided markets serve as information intermediaries by connecting participants on both sides. In this study, we focus on the coordination of participants in the P2P lending market using a coupon strategy as an incentive to attract investment. Using a twosided market model, we find that when a platform adopts the coupon strategy, (i) the platform utility and participants' utility are both greater and (ii) the number of participants is greater. In addition, as most research on two-sided markets and coupon strategy focuses on theoretical models, our study provides empirical support using data from Renrendai.com over 2018 to 2019.
\end{abstract}

\section{Information}

A two-sided market is roughly defined as a market in which one or several platforms enable interactions between endusers and attempt to get two (or more) sides "on the board" by appropriately pricing each side [1]. Due to cross-market benefits, market participation by the two sides depends on their expectations of the extent to which the other side of the market will participate. As market intermediaries, two-sided platforms face a challenging coordination problem that consists of attracting both participants. To examine this coordination problem, in this study, we introduce the investment in the coupon strategy by two-sided platforms.

There are several examples of two-sided platform markets adopting the coupon strategy, including e-commerce platforms such as Alibaba, Meituan.com, and Xiecheng.com, as well as online lending (e.g., Renrendai. com) in China and Amazon, eBay, and Lending Club outside China. However, studies of the coordination of the coupon strategy in these markets are scarce. Hagiu and Spulber introduce investment in first-party content as a strategic variable for two-sided platforms, show the interplay of platforms' pricing strategies, and define the coordination is the platform that matches the supplier and demander through a first-party content strategy so that the platform utility can be maximized when the utility of both sides is not less than 0 [2]. Dinerstein et al. explore the role of platform design in online markets, emphasizing the trade-off between reducing search friction by matching buyers to their most desired products and intensifying price competition among sellers [3]. Jung et al. found that a government-provided subsidy is optimal for platforms, consumers, and service providers [4].

Many studies of the coordination of the coupon strategy in a single market exist. The researcher provides a mathematical model that addresses the coordination of the schedules between a manufacturer and its suppliers in a decentralised supply chain $[5,6]$. Ali explores the coordination and incentive issues that may arise from the different types of collaborations between telecommunication firms and banks [7]. Reimers and Xie develop a model of consumer demand to empirically study whether (i) firms can use coupons as a means of price discrimination to attract new consumers without cannibalizing revenue from existing ones and (ii) these new consumers return to the firm after price promotion [8]. Edelman et al. analyse the conditions under which a business can benefit from issuing e-coupons [9], and Dholakia provides survey-based evidence that some businesses benefit from using e-coupons by finding new consumers [10]. Zhou et al. [11] studied the value of a 
cashback website to an e-shop in both centralised and decentralised settings. However, as two-sided markets are more complex than single markets $[12,13]$, and since it is necessary to coordinate the market participants on both sides, it is worth studying more in detail whether the coupon strategy in two-sided markets can coordinate both sets of participants.

In particular, we focus on the P2P lending market, which serves as an intermediary between borrowers and investors. And the participants have limited attention $[14,15]$. In the P2P lending market, borrower and investor participation represent a coordination game for which there are typically many Nash equilibria [2]. The use of the coupon strategy could thus serve as a strategic instrument to induce borrower and investor participation. We focus on the extent to which using the coupon strategy affects the number of participants and their utility. To this end, we propose an analytical model based on the two-sided market model $[2,16]$. Through the model analysis, we make three main findings. First, we find that the number of borrowers and investors is greater when the platform adopts the coupon strategy. Second, the utility of borrowers and investors is greater than for platforms that do not adopt the coupon strategy. Third, the profit difference between a platform adopting the coupon strategy and the one not doing so is inverted U-shaped with the coupon investment. Thus, the benefit to the platform increases under an appropriate coupon strategy.

We further build on the standard notion of unfavourable and favourable expectations [2, 17-19] to explore the ease with which a platform adopts the coupon strategy. The model analysis shows that if using a coupon strategy raises the number of borrowers and investors, the platform invests more into its coupon strategy when it is expected to be favourable. If platform utility decreases between favourable and unfavourable expectations, investments in the coupon strategy increase when the expectation are unfavourable.

Our empirical analysis employs detailed data from Renrendai.com, a leading P2P lending platform in China. Renrendai.com is an online market for unsecured personal loans. We analyse the annual reports of the platform from 2012 to 2019 and find that the platform has adopted the coupon strategy since the beginning of 2018. Therefore, this study mainly uses data from January 2018 to December 2019. Using regression analysis, we confirm that the results are consistent with the earlier results of the model. We find that the number of borrowers and investors is higher and that they have greater utility in the months with the coupon strategy. These results suggest that platform utility is greater with the coupon strategy. In addition, the empirical results show that the platform (Renrendai.com) adopts a coupon strategy under unfavourable expectations.

Theoretically and empirically, the main contribution is that we find two-sided market platforms promote the coordination of participants using the coupon strategy. Firstly, the results highlight that an appropriate coupon strategy increases the number of participants and their utility. Thus, it is verified that the impact of coupon on the externalities is not only a simple question of "quantity" but also a question of "quality", which extended the conclusion of Trabucchi et al. [20]. Although the platform is an information intermediary, it can optimize the trading results of participants, using strategies such as coupons, and promote the healthy development of the entire trading system. This result also complements the research of management perspective on two-sided platforms [12]. Secondly, the difference of the platform's benefits between adopting the coupon strategy and not doing so is inverted U-shaped with the coupon strategy investment. This implies that the effectiveness of using coupons to increase profits depends on the number of participants and the coordination ability of the platform, which supplements the conclusion of Bo et al. [6]. In addition, as most research on two-sided markets or coupon strategy focuses on theoretical models, our study bridges this gap in the literature by providing empirical support, shedding light on how managers can determine the number of coupons to be used under a coordination strategy.

The remainder of this paper proceeds as follows. Section 2 reviews the relevant literature. The two-sided market model is built, and the hypotheses are proposed in Section 3 . Section 4 describes the data and regression model. The empirical results are presented in Section 5. Section 6 provides robustness checks. Finally, we discuss our findings in Section 7.

\section{Literature Review}

Two primary streams of the literature relate most closely to our work: studies of two-sided markets and studies of the coupon strategy. First, several branches of the literature on two-sided markets yield insights; Trabucchi et al. [20] present an overview of the dynamics governing value mechanisms within a platform through the theoretical lens of the business model by using two prominent cases of multisided platforms. The other research also includes network externalities, network effects, and multiproduct pricing. Rochet and Tirole, for example, emphasize the importance of the relative price elasticity of demand on the two sides of the platform for determining pricing structures $[1,16]$. In addition, most analyses apply to specific industries: payment systems [21, 22], Internet-related intermediation [23-25], software and video games [18, 26, 27], and media markets [28]. Jullien [29] and Rochet and Tirole [1] propose useful roadmaps, while some researchers discuss the online lending market as a two-sided market, including Wei and Lin [30], Gao et al. [31], and Liu et al. [32]. However, studies of how to promote coordination in two-sided markets are scarce [2-4] as noted earlier. We study the influence of coupon strategy on the number of participants and their utility, and it is verified that the impact of coupons on the externalities is not only a simple question of "quantity" but also a question of "quality" [20].

Second, most research on the coupon strategy focuses on a single market. Lu and Moorthy [33] compared the effectiveness of coupons and rebates as price discrimination tools. The models of Levedahl [34], Narasimhan [35], and Dube et al. [36] pertain to coupons or rebates. Arcelus et al. develop a single-period decision model for a retailer facing uncertain and price-dependent demand by introducing a 
rebate to address excess demand [37]. Song and Fai Tso [38] research the influence of marketing strategy on the consumers' decision. Zhou et al. [11] developed a model to study the value of a cashback website to an e-shop in both centralised and decentralised settings. Moreover, they also demonstrate and compare the two parties' optimal strategies and their corresponding profits in both settings. In addition, Zhang et al. [39] studied how online retailers employing discounted prices affected customer behaviour in the short and long term using a randomised field experiment with data from the Alibaba Group. Due to the complexity of twosided markets, the impact of coupon strategy should be further studied, which complements the research of management perspective on two-sided platforms [12].

\section{Two-Sided Market Model}

To model a two-sided market, we focus on the P2P lending market. P2P lending connects a continuum of investors $i$ uniformly distributed over $[0, N]$ and a continuum of borrowers $j$ uniformly distributed over $[0, M]$. Pricing for borrowers is decided by the platform, that is, the expenditure of the borrower $\varphi$, including pay for investor $w$, and other management rates for the platform. In addition, the platform provides investors with $x$ coupon strategy. The platform incurs the costs of providing a coupon $c(x)$, which are increasing and convex in $x$.

3.1. Benchmark Model. In this section, we provide the case in which platforms do not adopt the coupon strategy as the benchmark model. Investor $i$ 's net benefit from joining the platform is

$$
U_{i}\left(W_{i}, P_{i}\right)=u\left(W_{i}\right)-P_{i},
$$

where $u\left(W_{i}\right)$ is the utility of investor $i$, which comes from borrowers. $u(\cdot)$ is increasing, and $W_{i}$ is the total return of investor $i$ by investing in borrowers. The platform charges service fee $P_{i}$ to investor $i$. The details are shown in Appendix.

Borrower $j$ 's net benefit from joining the platform is

$$
V_{j}\left(n_{j}, \varphi_{j}\right)=U_{j}-\varphi_{j},
$$

where $U_{j}=\sum_{i=1}^{n_{j}} u_{j i}$ is the utility of borrower $j, u_{j i}$ is the utility of borrower $j$ from investor $i$, and $n_{j}$ is the number of investors who invest in borrower $j . \varphi_{j}$ is the expenditure of the borrower $j$, including the pay for investors and other management rates for the platform.

We assume that borrower participation $m=m(P, \varphi)$ and investor participation $n=n(P, W)$.

The platform's profits are

$$
\Pi(P, \varphi)=\operatorname{Pn}(P, W)+(\varphi-W) m(\varphi, P)-C,
$$

where $C$ is the platform cost. The platform charges an average service fee $P$ to investors; $W$ is the average benefit of investors from borrowers, and $\varphi$ is the average expenditure of borrowers.
In particular, the number of investors in the platform is $n=n(P, W)=\max \{(u(W)-P / A) D, 0\}$, which has a positive correlation with investor utility, $A$ is the average investment of investors, and $D$ is a constant. The number of borrowers in the platform is $m=m(\varphi, P) \in[0, M]$.

3.2. Model under the Coupon Strategy. When the platform adopts the coupon strategy, investor $i$ 's net benefit from joining the platform is

$$
U_{i}\left(W_{i}, x, P_{i}\right)=u\left(W_{i}, x\right)-P_{i},
$$

where $u\left(W_{i}, x\right)$ is the utility that investor $i$ obtains from the platform and borrowers, including the coupon strategy of the platform and the return by investing borrowers. $W_{i}$ is the return of investor $i$ by investing in borrowers. We suppose that the investors' utility function $u(\because)$ is increasing, twice continuously differentiable, and concave or linear in each of its arguments. As is natural, investor utility is increasing in coupons and the benefit to borrowers. Thus, an investor joins the platform if and only if the expected net benefit is non-negative.

Borrower $j$ 's net benefit from joining the platform is

$$
V_{j}\left(n_{j}, x, \varphi_{j}\right)=U_{j}-\varphi_{j}-\phi,
$$

where $U_{j}=\sum_{i=1}^{n_{j}} \pi_{j i}(x) u_{j i}$ is the utility of borrower $j$. $\pi_{j i}(x)$ is the degree of investor $i$ 's willingness to invest in borrower $j, \pi_{j i}(0)=1$, and $\pi_{j i}(x) \in[0, H) . n_{j}$ is the same as equation (2). The function $\pi(x)$ can be increasing or decreasing depending on the coupon strategy. A borrower chooses to participate if the expected benefits are non-negative.

The game with the simultaneous entry of the borrower and investor has two stages. First, the profit-maximizing platform chooses the amount of coupon $x$ and the average fees $P$ and $\varphi$ for investors and borrowers, respectively. Second, borrowers and investors choose whether to join the platform based on the prices chosen by it and their expectations about participation by borrowers on the other side of the market. The equilibrium of the full game consists of the first-stage choices of platform, $\left(P^{*}, \varphi^{*}, x^{*}\right)$, and the resulting Nash equilibrium of the borrower and investor from their participation decisions in the second stage. There are multiple self-fulfilled participation equilibria for any vector $(P, \varphi, x)$ of platform choices.

The platforms' profits are

$$
\Pi(p, \varphi, x)=\operatorname{Pn}(x, P, W)+(\varphi-W) m(x, P, \varphi)-c(x)-C .
$$

The platform chooses coupon $x$ as well as the average service fee of investor $P$ and the average expenditure of borrower $\varphi$ to maximize profits, given the effects of its actions on the outcome of the participation subgame played by borrowers and investors. Therefore, maximizing the utility yields 


$$
\begin{aligned}
& \max _{P, \varphi, x}\{\operatorname{Pn}(x, P, W)+\varphi m(x, P, \varphi)-c(x)-C\}, \\
& \text { s.t. } U_{j}-\varphi_{j}-\phi \geq 0, \\
& u\left(W_{i}, x\right)-u\left(P_{i}\right) \geq 0 .
\end{aligned}
$$

According to $U_{i}\left(W_{i}, x, P_{i}\right) \geq 0$ and $V_{j}\left(n_{j}, x, \varphi_{j}\right) \geq 0$, the platform utility is maximized as follows:

$$
\begin{aligned}
& \max _{P, \varphi, x}\{\operatorname{Pn}(x, P, W)+(\varphi-W) m(x, P, \varphi)-c(x)-C\}, \\
& \text { s.t. } \pi(x) \overline{\mathrm{un}}-\varphi \geq 0, \\
& u(W, x)-P \geq 0,
\end{aligned}
$$

where $\pi(x)$ is the average degree of investors' willingness to invest in borrowers, $\bar{u}$ is the average utility of borrowers, and $u(W, x)$ is the average utility of investors. $\bar{n}=u(W, x)-$ $P / A m D$ is the average number of investors investing. The participation of borrowers is $m=m(P, \varphi, x)$ when $V_{j}\left(n_{j}\right.$, $\left.x, \varphi_{j}\right)<0, m=0$, and the platform reaches the service limit when $V_{j}\left(n_{j}, x, \varphi_{j}\right)>0, m=M$. And the participation of investors is $n=n(P, W, x)$, where $n=\max \{u(W, x)-P / A D, 0\}$.

3.3. Comparison of the Two Situations. Comparing equations (1) and (4), we find that the utility of investors is greater under the coupon strategy. Additional investigation leads to the first proposition. Table 1 summaries the notation.

Proposition 1. Under the coupon strategy, the utility of investors is greater $U_{i}\left(W_{i}, x, P_{i}\right)>U_{i}\left(W_{i}, P_{i}\right)$, and there are more investors.

Proposition 1 is proven as shown in Appendix. The platform increases its costs if it adopts the coupon strategy.

To study the influence of the coupon strategy on platform utility. Let equation (6) subtract equation (3), we have equation (9) as follows:

$$
\begin{aligned}
\Pi(P, \varphi, x)-\Pi(P, W)= & P[n(x, P, W)-n(P, W)] \\
& +(\varphi-W)[m(x, P, \varphi) \\
& -m(P, \varphi)]-c(x) .
\end{aligned}
$$

We suppose $\Pi=\Pi(P, \varphi, x)-\Pi(P, W)$, equation obtains the partial derivative of $x$ as follows:

$$
\Pi^{\prime}=\operatorname{Pn}_{x}(x, P, W)+(\varphi-W) m_{x}(x, P, \varphi)-c^{\prime}(x) .
$$

When $c^{\prime}(x)<P n_{x}(x, P, W)+(\varphi-W) m_{x}(x, P, \varphi)$, the difference between the platform's benefit from investing in the coupon strategy and not investing increases with $x$; when $c^{\prime}(x)>P n_{x}(x, P, W)+(\varphi-W) m_{x}(x, P, \varphi)$, the difference decreases with $x$; and when $c^{\prime}(x)=P n_{x}(x, P, W)+(\varphi-W)$ $m_{x}(x, P, \varphi)$, the difference is the maximized. Furthermore, we also find that the coupon investment $x$ is related to the number of participants. Proposition 2 summarizes these findings.

Proposition 2. The profit difference between a platform adopting the coupon strategy and not doing so is inverted $U$-shaped with coupon investment $x$. Therefore, the platform adopts an appropriate coupon strategy, and this brings about positive benefits.
3.4. Favourable and Unfavourable Expectations. Whether a platform has favourable or unfavourable expectations depends on the level of participation by both sides. A platform has favourable expectations (F platform) when borrowers and investors always coordinate at the equilibrium at the highest possible level of participation on both sides. On the contrary, a platform has unfavourable expectations (UF platform) when borrowers and investors always coordinate at the equilibrium at the lowest possible level of participation on both sides.

We first consider the $\mathrm{F}$ platform. It maximizes profit, which is

$$
\begin{aligned}
& \max _{P, \varphi, x}\left\{P\left[\frac{u(\mathscr{W}, x)-P}{A} D\right]+(\varphi-\mathscr{W}) M-c(x)-C\right\}, \\
& \text { s.t. } \pi(x) \bar{u}\left[\frac{u(\mathscr{W}, x)-P}{\mathrm{AM}} D\right]-\varphi \geq 0, \\
& u(\mathscr{W}, x)-P \geq 0
\end{aligned}
$$

where $\mathscr{W}$ is the maximum benefits of investors by investing in borrowers when the platform has the largest number of borrowers. Then, the platform's maximization problem becomes

$$
\begin{aligned}
\max _{P, x} \pi^{F}(P, x, \varphi)= & \max _{P, x, \varphi}\left\{[P+\bar{u} \pi(x)]\left[\frac{u(\mathscr{W}, x)-P}{A} D\right]\right. \\
& -c(x)-C-\mathscr{W} M\} .
\end{aligned}
$$

The first-order conditions determining the $F$ platform's optimal choices of investor price and coupon strategy are

$$
\begin{aligned}
P_{f} & =\frac{u\left(x_{f}, \mathscr{W}\right)-\bar{u} \pi\left(x_{f}\right)}{2}, \\
c^{\prime}\left(x_{f}\right) & =\frac{\left[u\left(x_{f}, \mathscr{W}\right)+\bar{u} \pi\left(x_{f}\right)\right]\left[u_{x}\left(x_{f}, \mathscr{W}\right)+\pi_{x}(x) \bar{u}\right]}{2 A} D,
\end{aligned}
$$

where $u_{x}(W, x)=(\partial u / \partial x)(W, x) ; \pi_{x}(x)=(\mathrm{d} \pi / \mathrm{d} x)(x)$.

Next, we consider the UF platform, which has few borrowers and investors. Assume that the number of borrowers $Y$ in the platform is not much larger than 0 . The optimization problem is

$$
\begin{aligned}
& \max _{P, w, x}\left\{P\left[\frac{u\left(\mathrm{~W}^{\prime}, x\right)-P}{A} D\right]+(\varphi-W) Y-c(x)-C\right\}, \\
& \text { s.t. } \pi(x) \overline{\mathrm{un}}-\varphi \geq 0, \\
& u(W, x)-P \geq 0,
\end{aligned}
$$

where $\mathrm{W}^{\prime} \leq \mathscr{W}$. The resulting platform profits are 
TABle 1: Parameter definitions.

\begin{tabular}{lc}
\hline Parameter & Define \\
\hline$i$ & Investor $i$ \\
$j$ & Borrower $j$ \\
$r_{i j}$ & The real interest rate of investor $i$ from borrower $j$ \\
$r_{a i j}$ & The nominal interest rate for an investor to invest in borrower $j$ priced by the platform \\
$A_{i j}$ & The biding amount of investor $i$ investing in borrower $j$ \\
$m_{i}$ & The number of borrowers invested by investor $i$ \\
$e_{i j}$ & The platform's service fee rate \\
$W_{i}$ & The return of investor $i$ by investing in $m_{i}$ borrowers \\
$P_{i}$ & The service fee charged by the platform to investor $i$ \\
$x$ & An amount of the coupon strategy \\
$U_{j}$ & The utility of borrower $j$ \\
$n_{j}$ & The number of investors who invest in borrower $j$ \\
$\varphi_{j}$ & The expenditure of borrower $j$ \\
$\pi_{j i}(x)$ & The investment intention of investor $i$ who invests in borrower $j$ \\
$A$ & The average investment of investors \\
$P$ & The average service of investors \\
$\varphi$ & The average expenditure of borrowers \\
$C$ & The platform cost \\
$\bar{u}$ & The average utility of borrowers \\
$m, n$ & The return of investors by investing in borrowers when the platform has the largest number of borrowers \\
$W$ & The average benefit of investors from borrowers \\
$c(x)$ & The platform's costs of providing coupons \\
$\mathscr{W}$ & The
\end{tabular}

$$
\begin{gathered}
\max _{P, x}\left\{P\left[\left(\frac{u\left(\mathrm{~W}^{\prime}, x\right)-P}{A}\right) D\right]+Y \pi(x) \bar{u} \max \right. \\
\left.\left[\left(\frac{u(W, x)-P}{\mathrm{AY}}\right) D, 0\right]-c(x)-\mathrm{YW}-C\right\} .
\end{gathered}
$$

The optimal investor price and coupon strategy for the UF platform are $\left(x_{U F}, P_{U F}\right)$. Calculating the first-order conditions in equation (15), we obtain $\left(x_{U F}, P_{U F}\right)$ as follows:

$$
\begin{aligned}
P_{U F}= & \frac{u\left(x, \mathrm{~W}^{\prime}\right)-\bar{u} \pi(x)}{2}, \\
c^{\prime}\left(x_{u f}\right)= & D \frac{\left[u_{x}\left(x, \mathrm{~W}^{\prime}\right)-\pi_{x}(x) \bar{u}\right]\left[u\left(x, \mathscr{W}^{\prime}\right)-\bar{u} \pi(x)\right]}{2 A} \\
& +D \frac{\bar{u} \pi(x) u_{x}(x, W)+\bar{u} \pi_{x}(x) u(x, W)}{A} .
\end{aligned}
$$

Based on equations (12)-(16), we propose two lemmas that characterise the platform's optimal choice of coupon strategy.

Lemma 1. With the entry of borrowers and investors, the $F$ platform's optimization problem is equivalent to solving $\max _{x} \Pi^{F}(x)$, where

$$
\Pi^{F}(x)=\max _{x}\left\{\frac{[u(x, \mathscr{W})+\bar{u} \pi(x)]^{2}}{4 A^{2}} D-c(x)-C-\mathscr{W} M\right\} .
$$

Lemma 2. With the entry of borrowers and investors, the UF platform's optimization problem is equivalent to solving $\max _{x} \Pi^{U F}(x)$, where

$$
\begin{aligned}
& \Pi^{U F}(x) \max _{x} \frac{[u(x, \mathscr{W})-\bar{u} \pi(x)]^{2}}{4 A} D+\bar{u} \pi(x) \frac{u(W, x)}{A} \\
& -c(x)-C-\mathrm{WY} .
\end{aligned}
$$

Let $\Delta(x)=\Pi^{F}(x)-\Pi^{U F}(x)>(<) 0$ represent the gain (loss) in profitability due to unfavourable expectations. The UF platform selects a higher (lower) investment in $x$ when $\Delta(x)$ is decreasing (increasing). Furthermore, we derive our main result (proven in Appendix), which compares platforms' investment under the coupon strategy.

Proposition 3. If coupon strategy $x$ raises the number of borrowers and investors, the F platform invests more in the coupon strategy. In addition, if $\Delta(x)=\Pi^{F}(x)-\Pi^{U F}(x)>0$, the UF platform selects a higher (lower) investment in $x$ when $\Delta(x)$ is decreasing (increasing).

3.5. Hypotheses. Vana et al. analyse panel data from a large cashback company and show that an increase in the probability that consumers make an additional online purchase raises the size of that purchase [40]. Moreover, the authors find that consumers are more likely to spend the money returned to them at generalist retailers, such as department stores than at other retailers. Sahni et al. found that discounts increase the demand for promoted products and revenue [41]. Overall, we thus propose the following hypotheses.

H1. The platform adopting the coupon strategy increases the number of investors. 
H2. To attract participants, the platform adopts the coupon strategy regardless of whether it faces unfavourable or favourable expectations.

H3. The utility of borrowers, investors, and the platform is larger when adopting the coupon strategy.

In a two-sided market, buyers experience positive network effects depending on the number of suppliers and suppliers receive similar positive network effects depending on the number of buyers [25, 27]. Therefore, we hypothesise the following:

H4. The platform adopting the coupon strategy increases the number of borrowers.

\section{Data and Methodology}

4.1. Data. China has regulated the P2P lending market in recent years. From the end of 2017, regulatory authorities issued many regulatory documents, and the regulations became stronger in 2019. Table 2 shows the main regulatory documents in 2018 and 2019. With the increase in supervision, many $\mathrm{P} 2 \mathrm{P}$ lending platforms have closed, leading to unfavourable expectations in the P2P lending industry. Table 2 shows that the regulatory authorities adopted more policies in 2019 than in 2018 as regulatory efforts became stronger.

The data are from Renrendai.com, one of the largest P2P lending platforms in China. Renrendai.com was founded in October 2010 and has the largest number of registered members for P2P lending in the country. By the end of 2019, it had about five million confirmed loans with a lending amount of 50 billion RMB and 200 million registered investors. In 2018, the platform has launched a coupon strategy as an incentive to attract investors and implemented more coupons in 2019 than in 2018, and the results are shown in Table 3. Therefore, the platform adopts the coupon strategy when facing unfavourable expectations, which implies that Hypothesis 3 is unsuitable for P2P lending markets.

To compare the changes before and after the coupon strategy, we use data from January 2017 to December 2019 in Renrendai.com. Table 4 shows the growth in annual transaction amount and the number of transactions between 2016 and 2019 (see also Figure 1). We find that the transaction amount increased from 2016 to 2017, then decreased in 2018, and the growth rate became negative in 2019. However, the growth in the annual number of transactions rapidly increased in 2019, with growth in the transaction number from 2016 to 2018.

Table 5 summarizes the descriptive statistics of investors (Panel A) and borrowers (Panel B) in 2017, 2018, and 2019. Panel A of Table 5 shows that the average number of investors does not decrease over time but does come more dispersed. Panel B shows that the number of borrowers increases and the amount of borrowing decreases, investors prefer to invest in short-term objects, and the yield decreases little. Hence, given the unfavourable expectations of P2P lending, whether the situation of Renrendai.com is related to the incentive strategy adopted by the platform deserves exploration through an empirical analysis.

4.2. Variables and Methodology. The data set from Renrendai.com includes loan information of 717 days. The main independent variable is the coupon strategy. The dependent variables include the number of borrowers and investors on day $t$, average investors' return on day $t$, and average borrower utility and platform utility on day $t$. Rysman uses advertising demand to express the effectiveness of advertisers. Thus, the utility of borrowers is a proxy for the number of investors in this study [22]. Qiu et al. study platform utility using trading volume or management fees [42]. Thus, we choose the average daily trading volume as a proxy of platform utility. In addition, as there are network externalities in two-sided markets $[1,21,43]$, we use the number of borrowers and investors on day $t-1$ and other listing information as the control variables. Table 6 defines the variables used in our analysis, and Table 7 provides the descriptive statistics for those variables between 2018 and 2019.

To study the influence of the coupon strategy on participants, the following empirical model is adopted:

$$
\begin{aligned}
\text { Borrower }_{t} & =\beta_{0}+\beta_{1} \text { Coupon }+\beta_{2} \text { interest }_{t-1}+\beta_{3} \text { Borrower }_{t-1}+\beta_{4} \text { lender }_{t-1}+\xi_{i t}, \\
\text { Lender }_{t} & =\beta_{0}+\beta_{1} \text { Coupon }+\beta_{2} \text { Borrower }_{t}+\beta_{3} \text { Lender }_{t-1}+\beta_{4} X+\xi_{i t}, \\
\text { Lreturn }_{t} & =\beta_{0}+\beta_{1} \text { Coupon }+\beta_{2} \text { Borrower }_{t}+\beta_{3} X+\xi_{i t}, \\
\text { Trading }_{t} & =\beta_{0}+\beta_{1} \text { Coupon }+\beta_{2} \text { Borrower }_{t}+\beta_{3} \text { Lender }_{t}+\beta_{3} X+\xi_{i t},
\end{aligned}
$$

where Coupon is coded 1 if the platform adopts a coupon strategy and 0 otherwise. interest $t_{t-1}$ is the average interest rate at time $t-1$. Borrower B $_{t-1}$ is the number of borrowers at time $t-1$, and lender ${ }_{t-1}$ is the number of investors at time $t-1 . X$ includes information on listings such as loan amount, loan terms, and interest rate. Borrower ${ }_{t}$ is the number of borrowers at time $t$, Lender ${ }_{t}$ is the number of investors and average utility of borrowers at time $t$, and Tra $\mathrm{ding}_{t}$ is the trading volume and the average platform utility at time $t$. Lreturn ${ }_{t}$ is the average utility of investors, which is calculated as follows: 
TABLE 2: The policy of online lending in 2018 and 2019.

\begin{tabular}{|c|c|}
\hline Time & Policy \\
\hline 2018.1. & "Notice of special rectification and acceptance of P2P lending risk" \\
\hline 2018.4. & "Notice of strengthening rectification and acceptance of asset management business through Internet" \\
\hline 2018.8. & "Notice of compliance inspection of P2P lending institutions" issued by the Internet finance regulation office \\
\hline 2019.1. & "No.1 Document" issued by the Internet finance regulation office \\
\hline 2019.4. & "Pilot work plan for the qualified record of online lending information intermediary institutions" \\
\hline 2019.7. & "Forum of the special rectification of network lending risk" \\
\hline 2019.9. & "Notice of strengthening the construction of a credit reporting system in the P2P lending field" \\
\hline 2019.11. & "Guiding opinions on the pilot transformation of online lending information intermediaries into small loan companies" \\
\hline
\end{tabular}

TABLE 3: The coupon strategies time provided by the platform.

\begin{tabular}{lc}
\hline 2018 & 2019 \\
\hline $1.10 .-1.17$. & $1.1 .-1.15$. \\
$5.8 .-5.21$. & $4.1 .-4.30$. \\
$5.28 .-6.18$. & $5.8 .-5.14$. \\
$7.2 .-7.17$. & $5.15 .-5.30$. \\
$8.8 .-8.28$. & $6.6 .-6.12$. \\
$9.13 .-9.30$. & $6.13 .-6.26$. \\
$10.1 .-10.8$. & $7.4 .-7.10$. \\
$11.8 .-11.21$. & $8.1 .-8.21$. \\
& $9.1 .-9.30$. \\
& $10.1 .-10.25$. \\
& $11.1 .-11.29$. \\
& $12.1 .-12.25$. \\
\hline
\end{tabular}

Note. There are 120 days and 226 days in which the platform adopts coupon strategy in 2018 and 2019 years, respectively.

TABLE 4: The growth of the transaction amount and number of transactions.

\begin{tabular}{ccc}
\hline Year & Transaction amount (\%) & Number of transactions (\%) \\
\hline 2019 & -78.78 & 179.8 \\
2018 & 38.47 & 49.34 \\
2017 & 94.86 & 105.16 \\
2016 & 84.70 & 16.17 \\
\hline
\end{tabular}

Note. Transaction amount is the year-on-year increase in transaction amount; and the number of transactions is the year-on-year increase in year-on-year increase in the number of transactions.

$$
\operatorname{Lreturn}_{t}=\text { bidamount }_{t} * \text { rate }_{t} \text {, }
$$

where bidamount ${ }_{t}$ is the average investment at time $t$ and rate $_{t}$ is the interest rate at time $t$.

\section{Empirical Results}

We begin our empirical analysis using OLS regression. Tables $8-10$ summarize the estimation results for borrowers, investors, and the platform, respectively. Table 8 shows the influence of coupon strategy on the number of investors and investors' return at time $t$. The relationship between the coupon strategy and the number of investors is significantly positive at the $1 \%$ level, as shown in column (1) of Table 8. There are similar results for investors' returns in column (5) of Table 8. When controlling for the information on listings, such as interest rate, we find that the coupon strategy has a positive impact on the number of investors and investors' returns (see columns (2) and (6) of Table 8). As shown in columns (3) and (7) of Table 8, the results are significantly positive at the $5 \%$ and $1 \%$ levels, respectively, when participant information is controlled. We obtain similar results in columns (4) and (8), which are controlled for using listing information and participant information at the same time. Furthermore, the influence of the control variables on the number of investors and the investors' returns is reasonable. For example, although a higher interest rate attracts more investors, the possibility of borrower default is higher. Therefore, there is a positive correlation with the number of investors and a negative correlation with the investors' return [44]. In columns (3), (4), (7), and (8), the number of investors at time $t-1$ has a positive impact on the number of investors at time $t$, suggesting herding behaviour. However, having more investors leads to less personal income. Therefore, Hypotheses 1 and 3 are supported.

Table 9 reports the results of the relationship between the coupon strategy and platform utility. As shown in column (1), the coupon strategy has a positive effect on the trading volume, which is significantly at the $1 \%$ level. As shown in columns (2)-(8), the results are also significantly positive at the $1 \%$ level when information on listings and the number of participants is controlled for. Meanwhile, when we control for information on listings and participants at the same time, the relationship between the coupon strategy and trading volume remains significantly positive, which is shown in column (9) of Table 9. Furthermore, we find that the loan term has a negative influence on the trading volume, whereas the number of borrowers and investors has a positive influence. Overall, the influence of the coupon strategy remains unchanged regardless of the influence of the other control variables. Platform utility is higher when the platform adopts the coupon strategy, supporting Hypothesis 3 .

Table 10 shows the baseline analysis of the influence of the coupon strategy on the number of borrowers at time $t$. We find that using coupons promotes the number of borrowers in the P2P lending platform in column (1) of Table 10 , which is significant at the $1 \%$ level. When the interest rate, the number of borrowers, and the number of investors at time $t-1$ are individually controlled for, the relationship between the coupon strategy and the number of borrowers at time $t$ is significant and positive at the $1 \%$ level, while those control variables are significant in columns (2), (3), and (4), respectively. Meanwhile, the result is significant at the 5\% level when controlled, the variables are controlled for at the same time, and the influence of the control variables is 


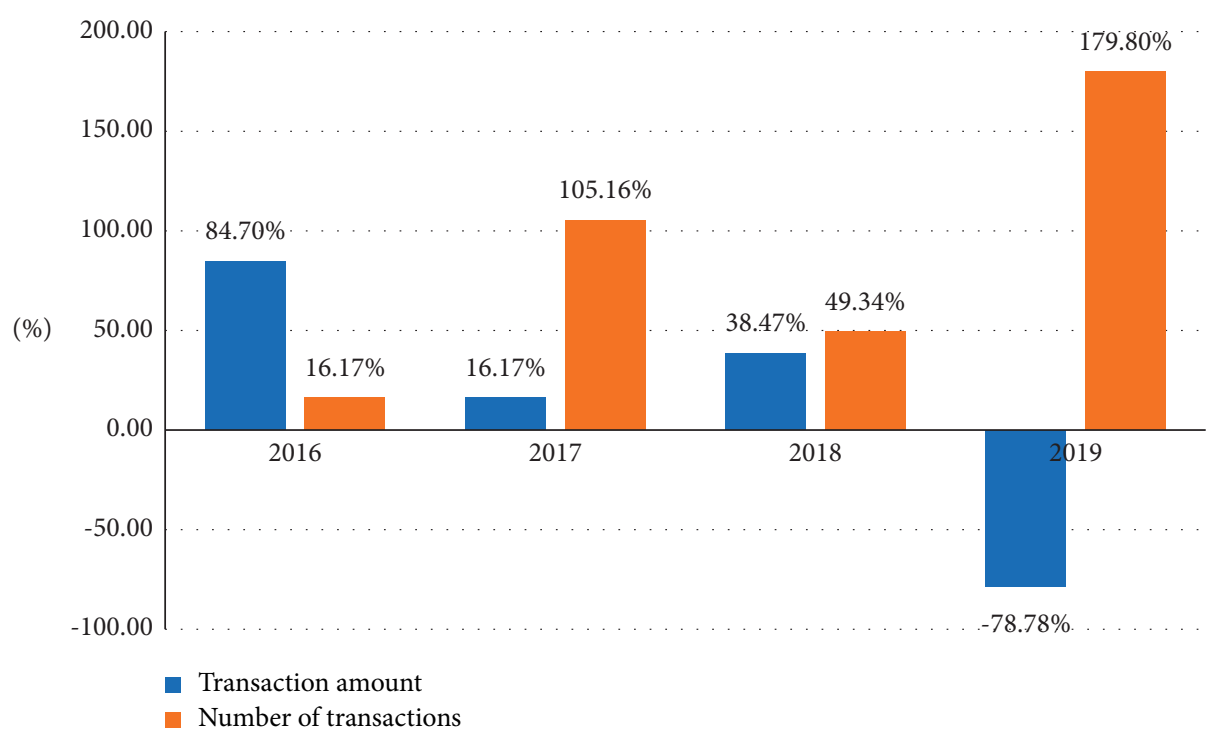

FIgURE 1: The growth of transaction amount and number of transactions.

TABLE 5: Descriptive statistics of participation number.

\begin{tabular}{|c|c|c|c|c|c|}
\hline \multicolumn{6}{|c|}{ Panel A. Descriptive statistic of the annual number of investors } \\
\hline Year & Obs. (Times) & $\operatorname{Max}$ & Min & Mean & Median \\
\hline 2017 & $475840(28860637)$ & 18337750 & 50 & 45823 & 10300 \\
\hline 2018 & $589791(27328645)$ & 23735150 & 50 & 51191 & 11200 \\
\hline 2019 & $439806(51176179)$ & 16047650 & 50 & 52553 & 12050 \\
\hline \multicolumn{6}{|c|}{ Panel B. Descriptive statistics of borrowers } \\
\hline Interest $_{17}$ & $272107(274269)$ & 11.76 & 8 & 9.82 & 10.2 \\
\hline Month $_{17}$ & 272107 (274269) & 48 & 3 & 32.13 & 36 \\
\hline Amount $_{17}$ & 272107 (274269) & 376000 & 1000 & 79501 & 73700 \\
\hline Interest $_{18}$ & $394618(409593)$ & 10.2 & 9 & 9.75 & 9.6 \\
\hline Month $_{18}$ & $394618(409593)$ & 48 & 12 & 31.01 & 36 \\
\hline Amount $_{18}$ & $394618(409593)$ & 197500 & 5000 & 73712 & 63600 \\
\hline Interest $_{19}$ & $1680165(3139456)$ & 10.8 & 9.6 & 10.21 & 10.2 \\
\hline Month $_{19}$ & $1680165(3139456)$ & 36 & 3 & 9.66 & 9 \\
\hline Amount $_{19}$ & $1680165(3139456)$ & 200000 & 300 & 7362 & 2100 \\
\hline
\end{tabular}

Panel A is descriptive statistics of the number of investors every year, the Obs. is the number of investors, and the Times is the number of bids times. Panel B is descriptive statistics of borrowers including listings' information, the Obs. is the number of borrowers, and the Times is the loan times. Interest $t_{17,18,19}$ is the interest rate in 2017, 2018, and 2019 year, respectively. Month ${ }_{17,18,19}$ is the loan term in 2017, 2018, and 2019 year, respectively. Amount $17,18,19$ is the borrowing amount in 2017, 2018, and 2019 year, respectively.

TABLE 6: Definition of variable.

\begin{tabular}{lc}
\hline Variable & Definition \\
\hline Borrower & The daily number of borrowers \\
Lender & The daily number of investors \\
Lreturn & Average daily investors' return \\
Trading & Average daily platform utility (average daily trading volume) \\
Coupon & The platform adopts the coupon strategy; 1 is the coupon strategy adopted in the month, otherwise 0. \\
Interest & Average daily interest rate \\
Amount & Average daily loan amount \\
Month & Average daily loan term \\
Bidamount & Average daily investment amount \\
\hline
\end{tabular}

Note. Borrower, Lender, and Lreturn are the dependent variables; Coupon is the main independent variable; and the others are the control variables.

constant in column (5). The results suggest a herding effect among borrowers and that investors have positive crossnetwork externalities with borrowers. This evidence supports Hypothesis 4.
In addition, we use the difference-in-difference methodology to test the causal effect of adopting the coupon strategy on the number of participants. Our treatment group comprises the months for which the platform adopted its 
TABLE 7: Summary statistics.

\begin{tabular}{|c|c|c|c|c|c|c|}
\hline Variable & Obs. & Mean & Std. & Min & Max & Med \\
\hline Borrower & 717 & 4906.496 & 7595.286 & 1 & 68114 & 1393 \\
\hline Lender & 717 & 50012.85 & 57445.14 & 2 & 235533 & 10608 \\
\hline Lreturn & 717 & 93.643 & 82.754 & 14.881 & 1170 & 60.172 \\
\hline Coupon & 717 & 0.529 & 0.499 & 0 & 1 & 1 \\
\hline Interest & 717 & 9.905 & 7.994 & 9 & 10.344 & 9.868 \\
\hline Month & 717 & 25.306 & 9.39 & 7.994 & 36 & 29.835 \\
\hline Amount & 717 & 68226.14 & 38517.03 & 1748.521 & 139886.8 & 80472.38 \\
\hline Bidamount & 717 & 955.412 & 871.48 & 145.888 & 13000 & 619.397 \\
\hline
\end{tabular}

Note. We identify participants for 717 days between January 2018 and December 2019 on Renrendai.com.

TABLE 8: The influence of coupon strategy on the number of investors and their return.

\begin{tabular}{|c|c|c|c|c|c|c|c|c|}
\hline & \multicolumn{4}{|c|}{ Lender } & \multicolumn{4}{|c|}{ Lreturn } \\
\hline & $(1)$ & $(2)$ & (3) & $(4)$ & $(5)$ & $(6)$ & $(7)$ & $(8)$ \\
\hline Coupon & $\begin{array}{c}1.213^{* * *} \\
(8.96)\end{array}$ & $\begin{array}{c}0.253 * * \\
(2.39)\end{array}$ & $\begin{array}{c}0.187 * * \\
(2.52)\end{array}$ & $\begin{array}{c}1.877^{* * * *} \\
(6.64)\end{array}$ & $\begin{array}{c}0.326^{* * *} \\
(6.29)\end{array}$ & $\begin{array}{l}0.017^{*} \\
(1.83)\end{array}$ & $\begin{array}{c}0.991^{* * *} \\
(4.99)\end{array}$ & $\begin{array}{c}0.681^{* * *} \\
(3.33)\end{array}$ \\
\hline Interest & & $\begin{array}{c}35.75^{* * *} \\
(10.96)\end{array}$ & & $\begin{array}{c}6.514^{* * *} \\
(3.23)\end{array}$ & & $\begin{array}{c}-10.61^{* * *} \\
(-7.54)\end{array}$ & & $\begin{array}{l}-1.525 \\
(-1.20)\end{array}$ \\
\hline Month & & $\begin{array}{c}-3.918^{* * *} \\
(-10.11)\end{array}$ & & $\begin{array}{l}-0.064 \\
(-0.25)\end{array}$ & & $\begin{array}{c}0.466^{* * *} \\
(2.79)\end{array}$ & & $\begin{array}{c}0.323 * * \\
\quad(2.04)\end{array}$ \\
\hline Amount & & $\begin{array}{c}1.400^{* * * *} \\
(8.58)\end{array}$ & & $\begin{array}{c}0.197 * * \\
(1.98)\end{array}$ & & $\begin{array}{l}0.003 \\
(0.04)\end{array}$ & & $\begin{array}{c}0.260^{* * *} \\
(4.18)\end{array}$ \\
\hline Lender $_{t-1}$ & & & $\begin{array}{c}0.642^{* * *} \\
(32.98)\end{array}$ & $\begin{array}{c}0.716^{* * *} \\
(29.14)\end{array}$ & & & $\begin{array}{c}-0.213^{* * *} \\
(-14.92)\end{array}$ & $\begin{array}{c}-0.193^{* * *} \\
(-12.84)\end{array}$ \\
\hline Borrower & & & $\begin{array}{c}0.485^{* * *} \\
(16.20)\end{array}$ & $\begin{array}{c}0.271^{* * *} \\
(7.15)\end{array}$ & & & $\begin{array}{c}-0.023^{* * *} \\
(-1.15)\end{array}$ & $\begin{array}{l}-0.028 \\
(-1.41)\end{array}$ \\
\hline $\mathrm{B} *$ Coupon & & & $\begin{array}{c}0.103^{* * *} \\
(2.83)\end{array}$ & $\begin{array}{l}0.063 \\
(1.59)\end{array}$ & & & $\begin{array}{c}0.087^{* * *} \\
(2.67)\end{array}$ & $\begin{array}{c}0.132^{* * *} \\
(3.99)\end{array}$ \\
\hline $\mathrm{C}$ & $\begin{array}{c}6.840^{* * *} \\
(4.51)\end{array}$ & $\begin{array}{c}-7.532^{* * *} \\
(-9.69)\end{array}$ & $\begin{array}{l}-0.101 \\
(-0.48)\end{array}$ & $\begin{array}{c}-16.741^{* * *} \\
(-3.56)\end{array}$ & $\begin{array}{c}4.437^{* * *} \\
(7.63)\end{array}$ & $\begin{array}{c}27.10^{* * *} \\
(8.08)\end{array}$ & $\begin{array}{c}6.491^{* * *} \\
(2.83)\end{array}$ & $\begin{array}{c}7.998^{* * *} \\
(2.69)\end{array}$ \\
\hline $\mathrm{N}$ & 717 & 717 & 716 & 716 & 717 & 717 & 716 & 716 \\
\hline$R^{2}$ & 0.10 & 0.533 & 0.844 & 0.848 & 0.10 & 0.376 & 0.525 & 0.574 \\
\hline
\end{tabular}

Note. The dependent variables are the number of investors and their return (remarked as Lender and Lreturn) at time $t$. The independent variable is the coupon (remarked as Coupon) at time $t$. Lender ${ }_{t-1}$ is the control variable, which is the number of investors at time $t-1$. Month, Amount, and Borrower are the control variable at time $t$, which are the listings' loan term, amount, and the number of borrowers, respectively. $\mathrm{B} *$ Coupon is the cross-term of the number of borrowers and coupons.

coupon strategy (defined as 1), and our control group includes noncoupon strategy months (defined as 0 ). Renrendai.com adopted its coupon strategy on 1 January 2018. Therefore, the control sample runs from 1 January 2017 to 31 December 2017, and the treatment sample runs from 1 January 2018 to 31 December 2018.

We estimate the effect of the coupon strategy in a regression framework using the following model:

$$
\begin{aligned}
Y= & \beta_{0}+\beta_{1} \text { time }_{i t} \times \text { Treated }_{i t}+\beta_{2} \text { time }_{i t}+\beta_{3} \text { Treated }_{i t} \\
& +\beta_{4} \text { Control }_{i t}+\xi_{i t},
\end{aligned}
$$

where $Y$ represents the number of borrowers and investors. time $_{i t}$ is a dummy variable defined as 1 for 2018 and 0

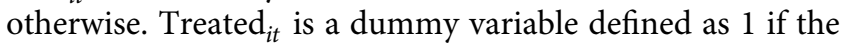
platform adopts the coupon strategy at time $t$ and 0 otherwise. Control $i t$ is a vector of the control variables including those in regressions (19) and (20), and $\xi_{i t}$ is the error term. The coefficient of the double interaction term captures the causal effect of the coupon strategy.
Without considering the control variables, Table 11 lists the differences between the treatment and control groups, which is the number of participants before and after the platform adopts the coupon strategy. When the platform adopts the coupon strategy, the average number of investors and borrowers increases significantly in the treatment group in column (6). The value of the difference in the average number of borrowers and investors is 0.678 and 0.108 , respectively, significant at the $1 \%$ level. Furthermore, in the difference-indifference model, we consider the other control variables controlled for in the basic regression. The results are shown in Table 12 . The coefficient $\beta_{1}$ is positively significant at the $1 \%$ level, which implies that the platform adopts an appropriate coupon strategy to raise the number of participants. Thus, Tables 11 and 12 provide support for Hypotheses 1 and 4 .

\section{Robustness Tests}

In this section, we provide robustness checks for our main results of the influence of the coupon strategy on the number of borrowers and investors as well as participants' utility. 
TABLE 9: The influence of coupon strategy on the trading number.

\begin{tabular}{|c|c|c|c|c|c|c|c|c|c|}
\hline & \multicolumn{9}{|c|}{ Trading } \\
\hline & (1) & (2) & (3) & (4) & (5) & (6) & (7) & (8) & (9) \\
\hline Coupon & $\begin{array}{c}1.192^{* * *} \\
(10.05)\end{array}$ & $\begin{array}{c}0.415^{* * *} \\
(4.48)\end{array}$ & $\begin{array}{c}0.263^{* * *} \\
(2.87)\end{array}$ & $\begin{array}{c}0.288^{* * *} \\
(3.00)\end{array}$ & $\begin{array}{c}0.279^{* * *} \\
(3.14)\end{array}$ & $\begin{array}{c}0.605^{* * *} \\
(5.74)\end{array}$ & $\begin{array}{c}0.392^{* * *} \\
(4.16)\end{array}$ & $\begin{array}{c}0.373^{* * *} \\
(3.96)\end{array}$ & $\begin{array}{c}0.183 * * \\
\quad(2.21)\end{array}$ \\
\hline Interest & & $\begin{array}{c}54.37^{* * *} \\
(4.16)\end{array}$ & & & $\begin{array}{c}23.94^{* * *} \\
(6.30)\end{array}$ & & & & $\begin{array}{c}13.24^{* * *} \\
(3.51)\end{array}$ \\
\hline Month & & & $\begin{array}{c}-2.110 * * \\
(-6.19)\end{array}$ & & $\begin{array}{c}-2.81^{* * *} \\
(-6.65)\end{array}$ & & & & $\begin{array}{c}-3.166^{* * *} \\
(-7.43)\end{array}$ \\
\hline Amount & & & & $\begin{array}{c}-0.866^{* * *} \\
(-3.93)\end{array}$ & $\begin{array}{c}0.639^{* * *} \\
(3.70)\end{array}$ & & & & $\begin{array}{c}0.887^{* * *} \\
(5.40)\end{array}$ \\
\hline Lender & & & & & & $\begin{array}{c}0.477^{* * *} \\
(7.23)\end{array}$ & & $\begin{array}{c}0.087 * \\
(2.37)\end{array}$ & $\begin{array}{c}0.125^{* * *} \\
(3.33)\end{array}$ \\
\hline Borrower & & & & & & & $\begin{array}{c}0.684^{* * *} \\
(4.01)\end{array}$ & $\begin{array}{c}0.609^{* * * *} \\
(4.29)\end{array}$ & $\begin{array}{c}0.434^{* * *} \\
(10.57)\end{array}$ \\
\hline $\mathrm{C}$ & $\begin{array}{c}6.687^{* * *} \\
(9.58)\end{array}$ & $\begin{array}{c}-7.70^{* * *} \\
(-3.29)\end{array}$ & $\begin{array}{c}3.63^{* * *} \\
(5.01)\end{array}$ & $\begin{array}{c}6.21^{* * * *} \\
(4.02)\end{array}$ & $\begin{array}{c}-5.84^{* * *} \\
(-5.05)\end{array}$ & $\begin{array}{c}2.403^{* * *} \\
(9.30)\end{array}$ & $\begin{array}{c}2.023^{* * *} \\
(9.92)\end{array}$ & $\begin{array}{c}1.757^{* * * *} \\
(7.56)\end{array}$ & $\begin{array}{r}-4.77^{* * *} \\
(-2.74)\end{array}$ \\
\hline $\mathrm{N}$ & 715 & 715 & 715 & 715 & 715 & 715 & 715 & 715 & 715 \\
\hline$R^{2}$ & 0.123 & 0.525 & 0.553 & 0.513 & 0.584 & 0.380 & 0.515 & 0.518 & 0.645 \\
\hline
\end{tabular}

Note. The dependent variables are the average daily utility of platforms (remarked as Trading, the average daily Trading volume) at time $t$. The independent variable is the coupon (remarked as Coupon) at time $t$. Lender and borrower are the control variable, which are the number of investors and borrowers at time $t-1$, respectively. Month, Amount, and Borrower are the control variable at time $t$, which are the listings' loan term, amount, and the number of borrowers, respectively. $t$ statistics are given in parentheses. ${ }^{* * *} p<0.01,{ }^{* *} p<0.05$, and ${ }^{*} p<0.1$.

TABLE 10: The influence of coupon strategy on the number of borrowers.

\begin{tabular}{|c|c|c|c|c|c|}
\hline & \multicolumn{5}{|c|}{ Borrower } \\
\hline & (1) & (2) & (3) & $(4)$ & (5) \\
\hline Coupon & $\begin{array}{c}0.972^{* * *} \\
(8.08)\end{array}$ & $\begin{array}{c}0.543^{* * *} \\
(5.29)\end{array}$ & $\begin{array}{c}0.524^{* * *} \\
(5.28)\end{array}$ & $\begin{array}{c}0.238^{* * *} \\
(3.15)\end{array}$ & $\begin{array}{c}0.180 * * \\
(2.41)\end{array}$ \\
\hline Interest $_{t-1}$ & & $\begin{array}{c}39.60^{* * *} \\
(17.83)\end{array}$ & & & $\begin{array}{c}12.36^{* * *} \\
(5.89)\end{array}$ \\
\hline Lender $_{t-1}$ & & & $\begin{array}{c}0.511^{* * *} \\
(19.66)\end{array}$ & & $\begin{array}{c}0.071 * * \\
\quad(2.27)\end{array}$ \\
\hline Borrower $_{\mathrm{t}-1}$ & & & & $\begin{array}{c}0.795^{* * *} \\
(34.90)\end{array}$ & $\begin{array}{c}0.757^{* * *} \\
(22.18)\end{array}$ \\
\hline $\mathrm{C}$ & $\begin{array}{c}6.840^{* * *} \\
(4.51)\end{array}$ & $\begin{array}{c}-83.66^{* * *} \\
(-16.49)\end{array}$ & $\begin{array}{c}2.219^{* * *} \\
(9.15)\end{array}$ & $\begin{array}{c}1.394^{* * *} \\
(8.54)\end{array}$ & $\begin{array}{c}-25.94^{* * *} \\
(-5.58)\end{array}$ \\
\hline $\mathrm{N}$ & 717 & 716 & 716 & 716 & 716 \\
\hline$R^{2}$ & 0.18 & 0.34 & 0.428 & 0.674 & 0.759 \\
\hline
\end{tabular}

Note. The dependent variable is the number of borrowers (remarked as Borrower) at time $t$. The independent variable is the coupon (remarked as Coupon) at time $t$. Interest $\mathrm{t}_{\mathrm{t}-1}$, Lender $\mathrm{t}_{\mathrm{t}-1}$, and Borrower $\mathrm{r}_{\mathrm{t}-1}$ are the control variables which are the interest rate, the number of investors, and borrowers at time $t-1$, respectively. $t$ statistics are given in parentheses. ${ }^{* * *} p<0.01,{ }^{* *} p<0.05$, and ${ }^{*} p<0.1$.

Because the data do not satisfy the normal distribution, we use a nonparametric Wilcoxon test to study the number of participants and trading volume before and after the implementation of the coupon strategy. Using data from January 2018 to December 2019, we divide the number of participants and trading volume into two groups: the platform does not adopt a coupon strategy at time $t$ (group 1) and the platform adopts a coupon strategy at time $t$ (group 2). Panel A of Table 13 shows that the number of borrowers in group 2 is significantly more than that in group 1 . In 2018, 2019 , or both years, the $p$-value is significant at the $5 \%$ and $1 \%$ levels. Panel B shows that the number of investors in group 2 is larger than that in group 1 at a significance level of $1 \%$, which implies that the coupon strategy can increase the number of investors. Panel $\mathrm{C}$ reports that the trading volume of group 2 is significantly higher than that of group 1 , which means that the platform increases its utility by adopting an appropriate coupon strategy.

Recall that our main results in Tables 8-10 use the full data sample (January 2018 to December 2019) to verify the hypothesis. We now examine whether these results are robust to including the subsamples of January 2018 to December 2018 and January 2019 to December 2019. We reestimate the regressions (19)-(21) and find that the results remain significantly positive at the $1 \%$ and $10 \%$ levels, as shown in Table 14. Although some of the results are not significant in columns (6), (9), (10), and (12), they are significant at the $10 \%$ level. In other words, these results are significant overall. Therefore, Hypotheses 1, 3, and 4 are again supported. 
TABLE 11: The difference of participants between experimental group and control group under coupon strategy.

\begin{tabular}{|c|c|c|c|c|c|c|c|}
\hline & \multicolumn{2}{|c|}{ Control } & \multicolumn{2}{|c|}{ Treat } & \multicolumn{2}{|c|}{ Difference } & \multirow{2}{*}{$\begin{array}{c}\text { DID } \\
(7)=(6)-(5)\end{array}$} \\
\hline & $(1)$ & (2) & (3) & $(4)$ & $(5)=(2)-(1)$ & $(6)=(4)-(3)$ & \\
\hline Lender & 9.813 & 9.921 & 9.606 & 10.393 & $\begin{array}{c}0.108 \\
(0.480)\end{array}$ & $\begin{array}{c}0.786^{* * *} \\
(4.04)\end{array}$ & $\begin{array}{c}0.678^{* * *} \\
(2.50)\end{array}$ \\
\hline Borrower & 5.853 & 6.369 & 6.020 & 6.782 & $\begin{array}{c}0.516^{* * * *} \\
(2.76)\end{array}$ & $\begin{array}{c}0.762 * * \\
(2.43)\end{array}$ & $\begin{array}{c}0.108^{* * *} \\
(2.61)\end{array}$ \\
\hline
\end{tabular}

Note. The Control group is that the day of the participants not affected by the coupon strategy, and the Treat group is that the day of the participants affected by the coupon strategy. $t$ statistics are given in parentheses. ${ }^{* * *} p<0.01,{ }^{* *} p<0.05$, and ${ }^{*} p<0.1$.

TABLE 12: The regression result of DID.

\begin{tabular}{lcc}
\hline Variables & Borrower & Lender \\
\hline time $\times$ Treate $d$ & $0.669^{* * *}$ & $0.731^{* * *}$ \\
& $(2.63)$ & -0.243 \\
time & $(3.85)$ & $(-1.06)$ \\
& $0.697 *$ & 0.086 \\
Treated & $(1.83)$ & $(0.380)$ \\
Control & $0.540^{* * *}$ & $\mathrm{Y}$ \\
$\mathrm{C}$ & $(4.52)$ & $\mathrm{Y}$ \\
$N$ & $-9.311^{* * *}$ & $(3.02)$ \\
$R^{2}$ & $(-8.10)$ & 0.350 \\
\hline
\end{tabular}

Note. The table provides estimation results from a regression in which the dependent variable is the number of borrowers and investors. time $\times$ Coupon is the cross-term of the time and coupon. time is a dummy variable equal to one if the time is 2018 year, otherwise 0 . Coupon is a dummy variable equal to one if platform adopts the coupon. Control is a vector of control variables that include the control variables in regressions (I) and (II). $t$ statistics are given in parentheses. ${ }^{* * *} p<0.01,{ }^{* *} p<0.05$, and ${ }^{*} p<0.1$.

TABLE 13: Wilcoxon test of the number of participants.

\begin{tabular}{|c|c|c|c|c|c|c|c|c|}
\hline & & G1 & & & G2 & & 7 & \\
\hline & Obs. & Mean & Std. & Obs. & Mean & Std. & 2 & $P$ \\
\hline & & & Panel & num & orrowers & & & \\
\hline B2019 & 129 & 3453.07 & 4680.706 & 236 & 11286.75 & 10007.894 & -1.888 & 0.034 \\
\hline B2018 & 210 & 1104.633 & 623.34 & 143 & 1238.83 & 676.88 & -8.752 & 0.000 \\
\hline B & 338 & 2003.35 & 3140.31 & 379 & 7495.58 & 9285.62 & -9.419 & 0.000 \\
\hline & & & Pane & e num & & & & \\
\hline L2019 & 126 & 74709.89 & 44990.68 & 236 & 104564.35 & 49969.51 & -3.871 & 0.000 \\
\hline L2018 & 210 & 3850.89 & 2558.79 & 143 & 5150.01 & 3412.31 & -3.871 & 0.000 \\
\hline $\mathrm{L}$ & 338 & 30904.06 & 44280.81 & 379 & 67054.45 & 62328.84 & -9.112 & 0.000 \\
\hline & & & Panel C. & umber & ling volume & & & \\
\hline T2019 & 140 & 3609.1 & 410.58 & 224 & 11548.77 & 672.24 & -9.060 & 0.000 \\
\hline T2018 & 216 & 877.59 & 32.99 & 135 & 978.23 & 46.45 & -1.967 & 0.029 \\
\hline $\mathrm{T}$ & 356 & 1951.78 & 177.122 & 359 & 7573.77 & 499.18 & -9.861 & 0.000 \\
\hline
\end{tabular}

Note. Table 13 shows the Wilcoxon test of the number of participants. Group 1 is that the platform does not adopt the coupon strategy in time $t$, and group 2 is that the platform adopts the coupon strategy in time t. B2019, L2019, and T2019 are the number of borrowers and investors in the 2019 year, and the trading volume in the 2019 year, respectively. B2018, L2018, and T2018 are the similar implication in the 2018 year. B, $L$, and Tare the overall situation of two years. 


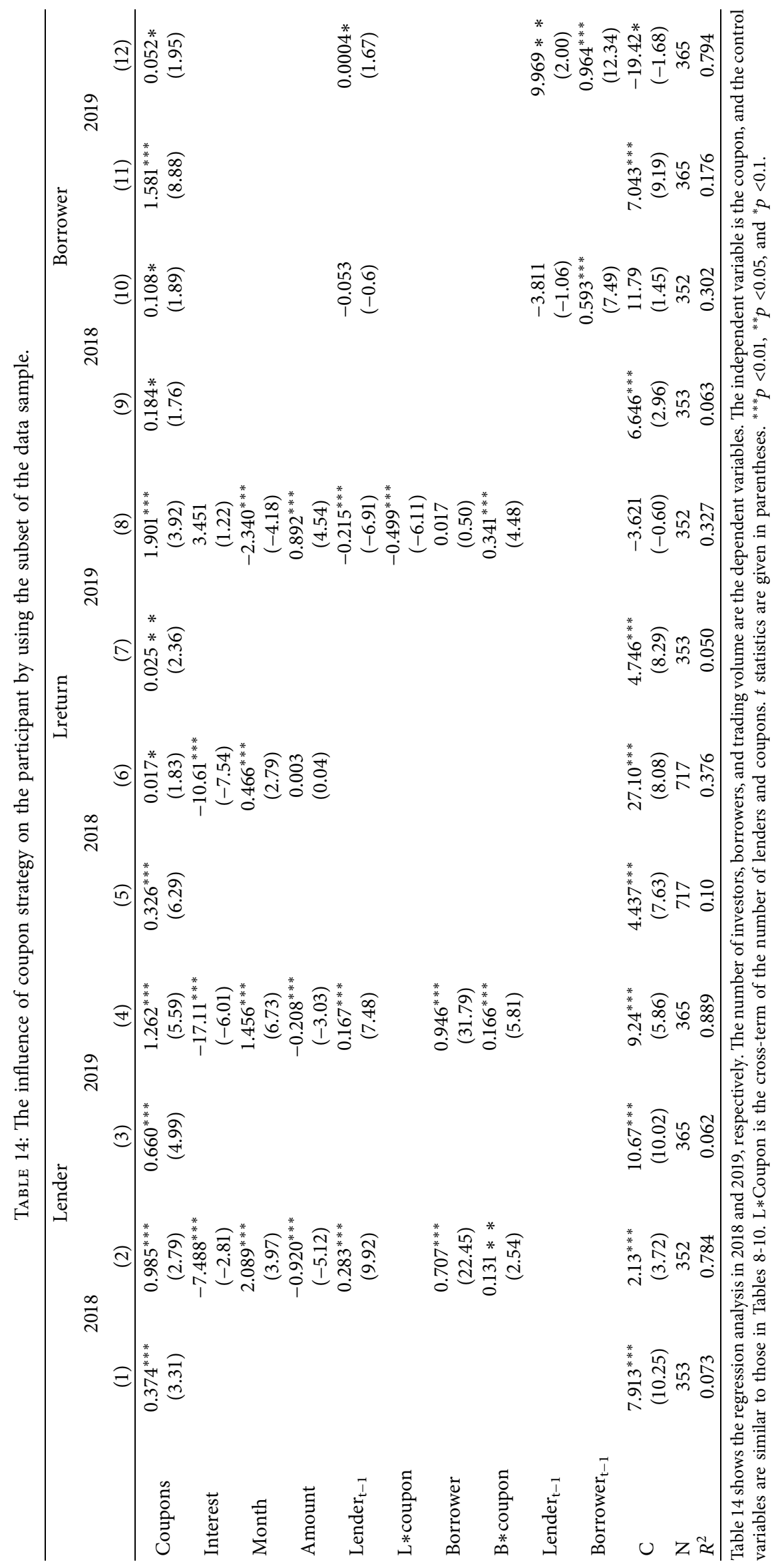




\section{Conclusions}

In this paper, we examine how adopting the coupon strategy affects investors' investment decisions and willingness of borrowers in two-sided platforms. Most research on twosided markets is based on theoretical models. Hence, we use the two-sided market model, which focuses on the incentive strategy of the platform, to produce empirically verifiable hypotheses, which we test using data from Renrendai.com.

Firstly, the benchmark model is established and then the adoption of the coupon strategy is added into the benchmark model. Finally, we compare the utility of investors, borrowers, and the platform as well as the number of participants in the two models. Under the coupon strategy, participants' utility and the number of participants were larger. Although the platform enjoys more participation and more benefits under the coupon strategy, it is further affected by the additional costs of running the coupon strategy. Overall, the platform utility is higher when the platform adopts an appropriate coupon strategy. Additionally, we find that the platform adopts a coupon strategy to attract investors regardless of whether it is expected to be favourable or not. If the difference between the utility under unfavourable and favourable expectations decreases gradually, the platform invests more in the coupon strategy when it is expected to be unfavourable.

Furthermore, the empirical results confirm our theoretical predictions, showing that the number of investors and borrowers is significant when the platform adopts a coupon strategy. The utility of participants is greater in the months in which the coupon strategy is adopted. Moreover, we find that Renrendai.com is more likely to adopt a coupon strategy when it is expected to be unfavourable.

While our analysis focuses on the P2P lending market, the conclusions can also be generalized to other markets. The twoside platform invests a coupon strategy that has yielded imperative guidance for the behaviour of managerial and participants. For example, for the managers of the two-sided market, who can analyse and summarize the number of participants every day and then put forward the most appropriate coupon strategy. Finally, this paper has some limitations. For instance, we did not consider borrowers, defaulting (credit risk), or other complex situations. Therefore, the influence of other management strategies and the corresponding problems are worthy of study in future research.

\section{Appendix}

\section{A. Proofs}

The return of investor $i$ is

$$
R_{i}=\sum_{j=1}^{m_{i}} r_{i j} A_{i j}-\sum_{j=1}^{m_{i}} \max \left\{\left(r_{i j}-r_{a i j}\right), 0\right\} A_{i j},
$$

where remark $e_{i j}=r_{i j}-r_{a i j}, m_{i}$ is the number of borrowers which invested by investor $i, r_{i j}$ is the real interest rate of investor $i$ from borrower $j$. $A_{i j}$ is the biding amount of investor $i$ investing borrower $j . r_{a i j}$ is the nominal interest rate for an investor invested in the borrower $j$, which priced by the platform. The platform charges service fee rate $e_{i j}$ to investor $i$ when invest borrower $j$. Then equation (A.1) is rewired as follows:

$$
R_{i}=\sum_{j=1}^{m_{i}} r_{i j} A_{i j}-\sum_{j=1}^{m_{i}} e_{i j} A_{i j}
$$

We suppose that $W_{i}=\sum_{j=1}^{m_{i}} r_{i j} A_{i j}=\sum_{j=1}^{m_{i}} w_{i j}$ indicates that the investor $i$ obtains the total return by investing in $m_{i}$ borrowers, and $P_{i}=\sum_{j=1}^{m_{i}} e_{i j} A_{i j}=\sum_{j=1}^{m_{i}} p_{i j}$ is the service fee charged by the platform to investor $i$.

Proof of Proposition 1. Comparing equation (1) to (4), we obtain

$$
U_{i}\left(W_{i}, x, P_{i}\right)-U^{b}{ }_{i}\left(W_{i}, P_{i}\right)=u\left(W_{i}, x\right)-u_{b}\left(W_{i}\right),
$$

$u(\cdot)$ is increasing, and the investors' utility function $u(\because)$ is increasing, twice continuously differentiable, and concave or linear in each of its arguments. Thus, $u\left(W_{i}, x\right)-u_{b}\left(W_{i}\right)$, and $n \geq n_{b}$.

Proof of Proposition 4. Assume that $x_{f}, x_{u f}$ are uniquely defined. We compare the first-order condition determining $x_{f}$ (equation (13)) with the one determining $x_{u f}$ (equation (16)). Let us plug $x_{f}$ instead of $x_{u f}$ in (16) taking (13) into account, then

$$
\begin{aligned}
\frac{\left[u_{x}\left(x_{f}, \mathscr{W}\right)-\bar{u} \pi_{x}\left(x_{f}\right)\right]\left[u\left(x_{f}, \mathscr{W}\right)-\bar{u} \pi\left(x_{f}\right)\right]}{2 A} D+D \\
\frac{\bar{u} \pi(x) u_{x}(x, W)+\bar{u} \pi_{x}(x) u(x, W)}{A}-c^{\prime}\left(x_{f}\right) \\
=\frac{\bar{u} D}{A}\left\{\pi\left(x_{f}\right)\left[u_{x}(x, W)-u_{x}\left(x_{f}, \mathscr{W}\right)\right]+\pi_{x}\left(x_{f}\right)\right. \\
\left.\quad\left[u(x, W)-u\left(x_{f}, \mathscr{W}\right)\right]\right\} .
\end{aligned}
$$

The investors' utility function $u(\because)$ is increasing, twice continuously differentiable, and concave or linear in each of its arguments $u_{x}\left(x_{f}, W\right)-u_{x}\left(x_{f}, \mathscr{W}\right)<0, u\left(x_{f}, W\right)-u\left(x_{f}\right.$, $\mathscr{W})<0$. Therefore, the expression on the right side of the equation is negative, so that $x_{f}>x_{u f}$.

\section{Data Availability}

The data were taken from the Renrendai.com platform.

\section{Conflicts of Interest}

The authors declare that they have no conflicts of interest.

\section{References}

[1] J.-C. Rochet and J. Tirole, "Two-sided markets: a progress report," The RAND Journal of Economics, vol. 37, no. 3, pp. 645-667, 2006. 
[2] A. Hagiu and D. Spulber, "First-Party content and coordination in two-sided markets," Management Science, vol. 59, no. 4, pp. 933-949, 2013.

[3] M. Dinerstein, L. Einav, J. Levin, and N. Sundaresan, "Consumer price search and platform design in internet commerce," The American Economic Review, vol. 108, no. 7, pp. 1820-1859, 2018.

[4] Q. Jung, B. Kim, M. Park, and W. Straub, "Innovation and policy support for two-sided market platforms: can government policy makers and executives optimize both societal value and profits?" Information Systems Research, vol. 30, no. 3, pp. 1-14, 2019.

[5] C. Shi and H. Lee, "Incentive alignment and coordination of project supply Chains," Management Science, vol. 63, no. 4, pp. 1011-1025, 2016.

[6] H. Bo, Y. Chen, H. Li, and L. Qi, "Time-sensitive Supply Chain disruption recovery and resource sharing incentive strategy," Journal of Management Science and Engineering, vol. 6, no. 2, pp. 165-176, 2021.

[7] T. Ali, Incentive and Coordination Issues in the Mobile Banking Industry of Pakistan, MIT Sloan School of Management, Cambridge, MA, USA, 2014.

[8] I. Reimers and C. Xie, "Do coupons expand or cannibalize revenue? Evidence from an e-Market," Management Science, vol. 65 , no. 1, pp. 1-15, 2019.

[9] B. Edelman, S. Jaffe, and S. D. Kominers, "To Groupon or not to Groupon: the profitability of deep discounts," Marketing Letters, vol. 27, no. 1, pp. 39-53, 2014.

[10] M. Dholakia, How Effective Are Groupon Promotions for Businesses?, Rice University, Houston, TX, USA, 2010.

[11] Y.-W. Zhou, B. Cao, Q. Tang, and W. Zhou, "Pricing and rebate strategies for an e-shop with a cashback website," European Journal of Operational Research, vol. 262, no. 1, pp. 108-122, 2017.

[12] D. Trabucchi and T. Buganza, "Landlords with no lands: a systematic literature review on hybrid multi-sided platforms and platform thinking," European Journal of Innovation Management, 2021.

[13] D. Trabucchi, S. Sanasi, A. Ghezzi, and T. Buganza, "Idle asset hunters-the secret of multi-sided platforms," Research-Technology Management, vol. 64, no. 1, pp. 33-42, 2021.

[14] Y. Li, J. W. Goodell, and D. Shen, "Comparing search-engine and social-media attentions in finance research: evidence from cryptocurrencies," International Review of Economics \& Finance, vol. 75, no. 4, pp. 723-746, 2021.

[15] Y. Hu, X. Li, W. Goodell, and D. Shen, "Investor Attention Shocks and Stock Co-movement: Substitution or Reinforcement?" International Review of Financial Analysis, vol. 73, 2021.

[16] J.-C. Rochet and J. Tirole, "Platform competition in two-sided markets," Journal of the European Economic Association, vol. 1, no. 4, pp. 990-1029, 2003.

[17] B. Caillaud and B. Jullien, "Chicken \& egg: competition among intermediation service providers," The RAND Journal of Economics, vol. 34, no. 2, pp. 309-328, 2003.

[18] A. Hagiu, "Pricing and commitment by two-sided platforms," The RAND Journal of Economics, vol. 37, no. 3, pp. 720-737, 2006.

[19] H. Halaburda and Y. Yehezkel, "Platform Competition under Asymmetric Information," American Economic Journal: Microeconomics, vol. 5, 2011.

[20] D. Trabucchi, T. Buganza, and R. Verganti, "Quantity or quality? Value creation in two-sided platforms," Technology
Analysis \& Strategic Management, vol. 33, no. 2, pp. 162-175, 2021.

[21] J. Wright and U. Kaiser, "Price structure in two-sided markets: evidence from the magazine industry," International Journal of Industrial Organization, vol. 24, no. 1, pp. 1-28, 2006.

[22] M. Rysman, "Competition between networks: a study of the market for yellow pages," The Review of Economic Studies, vol. 71, no. 2, pp. 483-512, 2004.

[23] M. Armstrong, Competition in Two-Sided Markets, Industrial Organization, Vienna, Austria, 2006.

[24] M. Rysman, "An empirical analysis of payment card usage," The Journal of Industrial Economics, vol. 55, no. 1, pp. 1-36, 2007.

[25] S. Li, Y. Liu, and S. Bandyopadhyay, "Network effects in online two-sided market platforms: a research note," Decision Support Systems, vol. 49, no. 2, pp. 245-249, 2010.

[26] G. G. Parker and M. W. Van Alstyne, "Two-sided network effects: a theory of information product design," Management Science, vol. 51, no. 10, pp. 1494-1504, 2005.

[27] J. M. Gallaugher and Y.-M. Wang, "Understanding network effects in software markets: evidence from web server pricing," MIS Quarterly, vol. 26, no. 4, pp. 303-327, 2002.

[28] M. Reisinger, L. Ressner, and R. Schmidtke, "Two-sided markets with pecuniary and participation externalities," The Journal of Industrial Economics, vol. 27, no. 1, pp. 1-26, 2009.

[29] B. Jullien, "Two-sided markets and electronic intermediaries," CESifo Economic Studies, vol. 51, no. 2, pp. 233-260, 2005.

[30] Z. Wei and M. Lin, "Market mechanisms in online Peer-toPeer lending," Management Science, vol. 63, no. 12, pp. 1-22, 2017.

[31] G.-X. Gao, Z.-P. Fan, X. Fang, and Y. F. Lim, "Optimal Stackelberg strategies for financing a supply chain through online peer-to-peer lending," European Journal of Operational Research, vol. 267, no. 2, pp. 585-597, 2018.

[32] H. Liu, H. Qiao, S. Wang, and Y. Li, "Platform competition in Peer-to-Peer lending considering risk control ability," European Journal of Operational Research, vol. 274, no. 1, pp. 280-290, 2019.

[33] Q. Lu and S. Moorthy, "Coupons versus rebates," Marketing Science, vol. 26, no. 1, pp. 67-82, 2007.

[34] J. W. Levedahl, "Marketing, price discrimination, and welfare: Comment," Southern Economic Journal, vol. 50, no. 3, pp. 886-891, 1984.

[35] C. Narasimhan, "Competitive promotional strategies," Journal of Business, vol. 61, no. 4, pp. 427-449, 1988.

[36] J.-P. Dubé, Z. Fang, N. Fong, and X. Luo, "Competitive price targeting with smartphone coupons," Marketing Science, vol. 36, no. 6, pp. 944-975, 2017.

[37] F. J. Arcelus, R. Gor, and G. Srinivasan, "Price, rebate and order quantity decisions in a newsvendor framework with rebate-dependent recapture of lost sales," International Journal of Production Economics, vol. 140, no. 1, pp. 473-482, 2012.

[38] L. Song and G. K. Fai Tso, "Consumers can learn and can forget - modeling the dynamic decision procedure when watching TV," Journal of Management Science and Engineering, vol. 5, no. 2, pp. 87-104, 2020.

[39] D. J. Zhang, H. Dai, L. Dong et al., "The long-term and spillover effects of price promotions on retailing platforms: evidence from a large randomized experiment on Alibaba," Management Science, vol. 66, no. 6, pp. 2589-2609, 2020.

[40] P. Vana, A. Lambrecht, and M. Bertini, "Cashback is cash forward: delaying a discount to entice future spending," 
Journal of Marketing Research, vol. 55, no. 6, pp. 852-868, 2018.

[41] N. Sahni, D. Zou, and P. Chintagunta, "Do targeted discount offers serve as advertising? Evidence from 70 field experiments," Management Science, vol. 63, no. 8, pp. 1-18, 2016.

[42] J. Qiu, F. Nie, M. Tong, and G. Hu, "The characteristics of two side market of third-party electronic trading platform-an empirical analysis based on online personal lending market," Journal of Management Science in China, vol. 19, no. 1, pp. 47-59, 2016.

[43] E. Argentesi and L. Filistrucchi, "Estimating market power in a two-sided market: the case of newspapers," Journal of Applied Econometrics, vol. 22, no. 7, pp. 1247-1266, 2007.

[44] F. Fisher and B. Guimaraes, "U.S. real interest rates and default risk in emerging economies," Journal of Money, Credit, and Banking, vol. 45, no. 5, pp. 967-975, 2013. 